\title{
WRITTEN NARRATIVES OF GRADE 5 LEARNERS WITH DEVELOPMENTAL LANGUAGE DIFFICULTIES: A GROUP DISCUSSION INTERVENTION STUDY.
}

Sharon Moonsamy \& Natalie Barnes

University of the Witwatersrand

\begin{abstract}
Increased demand on a learner's linguistic, cognitive and metacognitive abilities is expected at higher grades in schools. The application of cognitive and metacognitive strategies when learning is, however, not always automatic, therefore explicit mediation to retrieve and apply these processes appropriately, is essential. This paper aims to compare the linguistic experiences of Grade 5 learners with Developmental Language Difficulties (DLD) when writing a narrative, pre- and post-discussion intervention.
\end{abstract}

The intervention approach is grounded in Feuerstein (2006) and Vygotsky's (1934/1987) theories of cognitive development. This quantitative and qualitative study was a quasiexperimental, pre- and posttest design. The sample consisted of 10 Grade 5 learners from a remedial school. The pretest written narratives preceded the intervention phase and were followed by the posttest narratives. The macro- and microstructure of the written narratives were analysed, using an adapted framework based on Fey's (2001) and Moonsamy's (2009) analysis protocol.

Explicit discussions on writing processes should generalise to familiar and novel tasks required in all learning situations. The findings suggest that interventions, using group discussions, were beneficial for learners with DLD where knowledge was coconstructed. Improvements in microstructure were evident while the macrostructure remained the same at post-intervention. This study contributes to evidence-based practice for learner instruction in mainstream and special needs environments.

Keywords: written narratives; developmental language difficulties; group discussion intervention; macrostructure; microstructure

\section{BACKGROUND}

Learners with oral and written language difficulties are at risk for academic failure. They find it difficult to express the same emotions and thought patterns in writing as when speaking (Ferraro \& Palmer, 2005). Their written skills are limited; they are observed to use less descriptive vocabulary and complex sentence structures and less than adequate thought integration. This statement indicates that oral language might be easier for these learners to engage in than written language, because written text involves more complex cognitive processes, with due cognisance of the reader's perspective for coherence and clarification.

Given the prerequisite of written language for learning in higher grades, learners with language difficulties will need support to access the curriculum. This paper, therefore, argues 
for an enhanced written language intervention that focuses on developing coherent and cohesive texts in learners.

For written language interventions to be relevant, learners have to be assessed. In the current South African context, satisfying the requirements of assessment is complex. Language assessments in South African school-aged learners continue to be a challenge for SpeechLanguage therapists (SLTs) mainly due to the absence of appropriately normed measures (Pascoe \& Norman, 2011). South African professional organisations and training programmes have yet to allocate budgets for large-scale research into formulating and norming materials to assess communication disorders. Most SLTs are also not equipped to conduct contextually appropriate assessments because of the country's diverse languages and cultures (Mdlalo, 2013).

This, nevertheless, does not negate the assessments required for learners with language impairments, delays and differences as they require support in the classroom. To mitigate this challenge, structured qualitative measures, such as narratives are fundamental in evaluating school-aged language skills. Furthermore, if interventions are to focus on written text, assessments of written outputs would be required. This manifests in a second challenge obtaining written narratives.

SLTs are familiar with obtaining oral narratives but not with written narratives to the same extent. Nonetheless, the latter are foundational for school-aged learners as written language surpasses oral language in the higher grades (Owens, 2014). Since many South African schools have English as the language of learning and teaching (LOLT), written narratives in English are a prerequisite of the South African CAPS curriculum. Several studies on narratives are available internationally and (less so) locally. According to Spencer and Petersen (2020), research interest in narrative intervention has recently increased. Most of these studies examine linguistic coherence and cohesion (Moonsamy, Jordaan \& Greenop, 2009) but few published studies examine written narratives following an intervention phase.

The purpose of this paper is to examine the changes in learners' written narratives following an intervention. The authors argue that explicit interventions in creating awareness of the writing process when formulating a narrative is essential, thereby influencing the writer to produce coherent outputs.

\section{THEORETICAL FRAMEWORK AND LITERATURE REVIEW}

This intervention study is grounded in Vygotsky's sociocultural and constructivist theory in the Zone of Proximal Development (ZPD) (Kozulin, 2015) as well as Feuerstein's mediated learning theories (MLE) (Tzuriel, 2013; Tzuriel \& Caspi, 2017) as these theories form the framework for the intervention.

The relationship between these theories and their influence on the study are briefly explained. Mediated learning experience (MLE) is a dynamic and intentional process conducted by a more knowledgeable other within the ZPD. MLE is characterised by the quality of the interaction between an individual and their environment (Feuerstein, Feuerstein, Falik \& Rand, 2006). The effectiveness of the interaction between the researchers and the learners should therefore impact the outcomes of the written narrative intervention. The ZPD further refers to the support the researchers provided to the learners through discussion on the writing process. 
As indicated in research (Scanlon, Anderson \& Sweeney, 2011; Moonsamy \& Carolus, 2019), Vygotsky and Feuerstein's theories support the argument that the quality of the learning experience that learners are exposed to is the main contributing factor to effective learning and scholastic progress. Thus, by examining the writing practices of the Grade 5 learners in the current study, the authors established their writing behaviours, informing the support trajectory. The constructivist framework is appropriate for this study as the SLT 'scaffolded' the learning through reflective practice. Therefore, literacy development can be facilitated through effective interaction between teachers or therapists and learners.

This was evident in a literacy study by Tayob and Moonsamy (2018) where SLTs and caregivers collaborated on MLE principles. Mediational skills were then transferred to children in the context of an orphanage. The term developmental language disorder (DLD) is used in this paper to refer to learners with a language-based learning difficulty (Gillam, Mecham \& Gillam, 2020).

\section{Children with DLD}

Children with DLD are described as having specific language and learning difficulties that interfere with their educational and social progress because communication is a foundational skill for learning (Vinson, 2012). Moreover, they display language, literacy and executive function (EF) difficulties that influence their writing abilities negatively (Seiger-Gardner, 2010). These learners do not allocate appropriate cognitive resources to tasks due to their EF difficulties. Dunn and Finley (2010) described their students who displayed poor cognitive resource allocation as spending too much mental energy on spelling or handwriting rather than spending the energy on story generation.

Such EF difficulties highlight the importance of explicit interventions and provide a rationale for the study. Koutsoftas (2020) indicates that difficulties across the five domains of language (syntax, morphology, phonology, semantics and pragmatics) are also evident across the four modalities (listening, reading, speaking and writing). Limitations in any of these domains will impair cognitive processing, writing and narrative production. Hence, this study's focus is to provide explicit instruction on writing processes to improve learners' narrative writing skills.

\section{Learning Support Contexts}

Learners with DLD are expected to manage their scholastic development in a mainstream school context as the current education policy in South Africa is one of inclusion. However, due to limited or absent resources in the form of support services offered by SLTs, occupational therapists (OTs) and learning support or remedial therapists; many of these learners with learning difficulties fail to thrive. However, some of these learners attend public or private remedial schools where learning support services are indeed available. South African public schools with support services are fewer than private schools and are referred to as full-service schools. The learners from this study attended a private learning support school. The researchers explored the written language and narratives of these learners diagnosed with DLD and this provided an understanding of their engagement in their learning context. 


\section{Written Language}

The relationship between cognition and language is well documented in the literature (Owens, 2014; Vinson, 2012). However, for this paper's purpose, reference will be made to the cognitive process but will not be discussed in-depth. Instead, the focus will be on the intervention in the writing process.

Written language requires cognitive-linguistic integration. Since written words can be chosen with greater deliberation and thought, a written argument can be extraordinarily sophisticated, intricate and lengthy. Learners with DLD experience great difficulty with these precise writing components. Written language is driven by logic, organisation and explicitness which require EF that learners with DLD find difficult to apply. Self-regulation, an EF process, needs to be present in quality writing. According to Harris, Schmidt and Graham (1997), writing is described as a flexible, goal-directed activity. Furthermore, they state that writing is scaffolded by a rich source of cognitive processes and strategies for planning, text production and revision. Mature writers also engage in purposeful and active self-direction of these writing processes and strategies. Complex written language requires increased sentence length and a composite language style (Vinson, 2012). Linguistic complexity and style are areas that are frequently problematic for learners with learning difficulties.

Consequently, such learners avoid or show reduced engagement in written tasks (Ferraro \& Palmer, 2005). Gillespie and Graham (2014) concur that learners with writing difficulties give up on writing tasks due to their difficulty in engaging their working memory. Furthermore, these learners experience negative emotions associated with their writing difficulties (Harris et al., 1997). From these authors it can be deduced that learners with learning difficulties require support to develop their written skills. In South Africa, learners with language difficulties are expected to follow the CAPS curriculum; the learning outcomes of listening, speaking, reading, writing, problem-solving and reasoning are thus included.

Writing is one of the most complex modalities to develop and requires strong foundational skills in oral language (Levey, 2014). Writing processes include amongst others, prewriting, drafting, editing and publishing (DoE, 2012). Instruction is indicated in CAPS but implementation cannot be confirmed and would need ethnographic research methods. The focus on writing at schools should develop writing forms in general, but fewer published studies on strategies that create awareness of the writing process are noted.

This paper, therefore, examined the impact of an intervention in creating a conscious awareness of the writing processes when formulating a narrative.

\section{Interventions on Writing Support for Learners}

Published research on writing interventions has indicated that support strategies benefit learners with writing difficulties (Dunn \& Finley, 2010; Gillespie \& Graham, 2014; Lawrence \& Harrison, 2014). Dunn and Finley (2010) cite several strategies including WWW, W=2, H=2 question strategy (What, Where, When) (2x Why) and (2x How) by Graham and Harris, and POW (Plan, Organise \& Write) strategy by Saddler, Moran, Graham, and Harris, amongst others. They found that when strategies were explicit, students could produce more text, plan and include key elements in the story. They also used art materials to encourage students to visually depict their story elements. In addition, the strategy of 'Ask, 
Reflect, Text' was used, which provided an avenue for the children to develop their thinking processes around writing. These studies highlight the importance of developing thinking skills in young writers albeit in locations different to South Africa and since context impacts writing outcomes (Witt, 1998), the context must be considered when analysing the personal narratives in this study.

\section{Narrative Writing}

Narratives were selected as the writing genre in this study because narratives are a selfinitiated, self-controlled and decontextualised form of organised discourse (Owens, 2014). Learners in Grade 5 are more familiar with narratives than expository text, as the latter would only have been introduced to them in Grade 4.

Narratives can occur in both written and oral form; different types of narratives place different demands on cognitive processing. Subsequently, a learner's ability to produce narratives is related to their competence in language, cognitive development and literacy acquisition. For this paper, the focus is on written personal narratives since that places a greater demand on the learner's cognitive and linguistic abilities.

Personal written narratives require integrating EFs and language knowledge to create text, making it a highly complex process (Vinson, 2012). Written narratives are an expression that entails identifying a resolution to a central problem using the medium of language. Owens (2014) posits that adequate coherence in the 'story grammar' is essential for these resolutions to be met systematically and sequentially. Learners with DLD experience great difficulty with expressive elaboration, where the storyteller is expected to go beyond information transmission whilst creating a theme, structure, story genre and mood.

Metacognitive verbs, metalinguistic verbs and elaborated noun phrases play a large role in expressive elaboration. These literal features are essential for relating the ordered relationships between events in complex narratives (Owens, 2014). Learners with DLD, therefore, use these literal language features less frequently. In addition, prior knowledge plays a significant role as the learner needs to draw from their cultural experiences to produce age-appropriate written narratives. Hence, the linguistic and cognitive features of narratives, combined with contextual and cultural perspectives should be considered when analysing oral and written narratives (Witt, 1998). The researchers in the current study reflected on the learners' culture and context when examining the narrative outputs, both pre- and postintervention.

\section{Narrative Analyses}

According to Nelson (2009), a narrative structure has two essential dimensions that must be assessed: macrostructure and microstructure. The macrostructure, also referred to as the story grammar, involves the story's components: its characters, settings, problem and resolution, and gives the story coherence. The microstructure provides cohesion, as the lexical aspects tie the components together (Owens, 2014). Moreover, sequence or temporal features are fundamental to narratives, providing the order and time of events respectively.

The macro- and microstructure components share a relationship. Thus, analysis of these two components requires an interrelated interpretation. Given this relationship between microand macrostructure, it was anticipated that the learners with DLD would have difficulty with 
both aspects of narratives. This assumption suggests that such language deficits may be due to reduced information and language processing capacity, which are not uncommon in learners with DLD (Owens 2014).

Macrostructural analysis involves analysing the story grammar components which provide an organisational pattern to narratives that aid in information processing (Owens 2014). Different methods of analyses are described in the literature. The method selected for this study is detailed in the section on methodology and is based on the frameworks of Fey (2001) and Moonsamy et al. (2009). Children with DLD produce fewer mature episodes than their typically-developing, age-matched peers (Moonsamy et al., 2009). Mature episodes refer to narratives that include all the components of the story grammar (characters, setting, plots, problems and resolutions). Hence, children with DLD make fewer complete setting statements and are less likely to include response, attempt and plan statements in their narratives. Inter-episodic relations are also weaker in the narratives of these children. In general, typically-developing children produce all story grammar elements by the age of 10 (Owens 2014), therefore, a group from the age range 10-13 year-olds were recruited for the study, as they should have established oral narrative structures.

Analysis of microstructure differs from that of macrostructure as several microstructural components vary significantly with age. Microstructure includes cohesive devices, reference, substitution, ellipsis, conjunction and lexical items (Owens, 2014). To tell an effective story, narrators should use cohesive devices that carry concepts across utterances. The three major categories of cohesive devices are referential, conjunctive and lexical cohesion. Children with DLD exhibit difficulty communicating well-organised, coherent narratives due to their inability to effectively utilise cohesive devices (Owens 2014). A detailed analysis of the microstructure applied in the current study is explained in the methodology. The authors argue that explicit instruction to learners that creates awareness in their metacognitive processes will translate into appropriate schemas, resulting in improved written narratives. Explicit instruction that focuses on writing processes can only occur in classrooms that operate on a constructivist framework (Moonsamy, 2014). These classrooms are therefore referred to as Thinking Classrooms.

\section{Thinking Classrooms}

Thinking Classrooms do not occur automatically because effective thinking is not always spontaneous (Moonsamy, 2011). Thinking Classrooms are shaped by intentional and explicit mediation prompted by the teacher to support the acquisition of linguistic and cognitive skills - creating metacognitive awareness in learners. Generating metacognitive awareness is significant since research findings strongly suggest that Thinking Classrooms are a promising direction in education, both locally and internationally. Such instruction is, however, not declared mandatory in general education practice (Moonsamy 2014). Learners have to be assisted in acquiring a repertoire of cognitive and metacognitive skills and strategies to become aware of their thinking, monitor their thinking and consequently, learn more effectively. Reflective thought is achieved by ensuring optimal classroom conditions for successful cognitive instruction (McGuiness 2005).

Moonsamy (2014) highlighted that even though the South African education curriculum has a constructivist approach, no reference to explicit cognitive instruction is indicated. The absence of explicit cognitive instruction in the curriculum will prevent the development and application of new knowledge schemas and strategy transfer. Hence, the importance of 
mediated learning and the inclusion of explicit cognitive instruction (process) and the curriculum's content is recommended. This premise motivates the intervention applied in the current study.

This paper describes the experience of school-age learners with DLD when writing a narrative subsequent to an intervention. The study first considered the teacher's linguistic, cognitive and metacognitive strategies for written narrative purposes, which highlighted and informed the intervention discussion on writing processes without explicitly telling learners to apply these strategies. The authors argue that explicit discussions on writing processes should translate into improved written outputs as learners develop an awareness of self, task and strategy. The research question, therefore, examined the changes evident in the learners' written narratives following an intervention.

\section{RESEARCH METHODOLOGY}

This study was a mixed-method, quasi-experimental study that employed a pre- and posttest design. The primary aim examined the changes in Grade 5 learners' written narratives following an intervention designed to create an awareness of the narrative writing process. The secondary aims were to examine the learners' narratives' (1) macrostructure and (2) microstructure pre- and posttest.

A pilot study was first conducted with one learner who was not included in the primary sample. Nonprobability purposive sampling was used in the main study to select a sample meeting prespecified inclusion/exclusion criteria (Table 1) (Leedy \& Ormrod, 2005). Ten English First Language (EFL) Grade 5 learners of mixed gender, within the 10-13-year age range were selected. They attended the same school for children needing learning support, following a diagnosis of DLD, as confirmed by their school records. Table 1 shows the inclusion and exclusion criteria for recruiting participants.

Table 1: Inclusion/Exclusion criteria for participant recruitment.

\begin{tabular}{|l|l|}
\hline Inclusion & Exclusion \\
\hline - $\quad$ Learners between the ages of 10 and 13. & - $\begin{array}{l}\text { Learners not meeting the inclusion } \\
\text { criteria. }\end{array}$ \\
- $\begin{array}{l}\text { English First Language speakers. } \\
\text { - Learners in Grade 5. }\end{array}$ & $\begin{array}{l}\text { Learners attending the same school for } \\
\text { children needing learning support. }\end{array}$ \\
- Learners diagnosed with DLD. & $\begin{array}{l}\text { informed consent. } \\
\text { Learners who did not provide informed } \\
\text { assent. }\end{array}$ \\
& - $\begin{array}{l}\text { Learners who were absent at either the } \\
\text { first or the second narrative writing task. }\end{array}$ \\
\hline
\end{tabular}

Gender was not specified to secure unbiased cognitive and metacognitive strategy use (Nelson, 2013). The age range certified that metacognitive and metalinguistic processes should have emerged per Piaget's formal operational stage (Cockcroft, 2009). However, learner grade, not learner age, was used to determine skill levels within the learning support context. Thus, learners were at a similar academic skill level. Only EFL speakers were selected to ensure that language delay, not language difference, could be confirmed. This criterion was included as children with language differences have age-appropriate language skills in their native language (Prezas \& Jo, 2017) and therefore should not have a language delay as assessed in this study. Learners who were absent at either the first or the second 
narrative writing were excluded from the study to avoid skewing the pretest/posttest format of the study and rendering the results unreliable.

Ethical clearance from the university's Ethics Committee was obtained and all ethical parameters were adhered to (Protocol No: H14/02/20). Whilst the current study attempted to investigate the learners' written skills, it did not expose them to any additional risk, such as potentially harmful themes or a discomforting context. Nevertheless, counselling and speechlanguage therapy referrals and services were available to the learners, should the research have generated emotional distress.

Each learner wrote a narrative based on a topic provided: 'An exciting fun event that you were involved in' or 'My best holiday ever and why it was my favourite'. The learners were given 30 minutes to complete the narrative writing task in a group setting, overseen by the researchers in the pretesting phase.

The researchers then conducted a focus group discussion during the intervention phase using an age-appropriate narrative as a reference. Learners' perceptions of good narrative writing were discussed via a dynamic interaction that allowed learners to actively control their narrative development by describing what they believed to be appropriate cognitive and metacognitive strategies to produce successful, engaging narratives. A set of guiding, openended questions (Appendix 1) was used as discussion points and were grouped as planning, monitoring and evaluating strategies to guarantee that the intervention followed a sequential pattern. These categories included all the necessary linguistic, cognitive and metacognitive strategies involved in a writing task. Discussion on the stories that learners had read was included so that they could link their learning to prior experience. Owens (2014) indicated that prior learning is necessary for learners to create a connection to new learning. The discussion created the link between stories read and writing processes.

All learners participated in this focus group discussion to ensure ethical practice; it would have been unjust to afford the opportunity to obtain potentially beneficial academic instruction only to some learners. Video recording (with permission) was utilised for the researchers to analyse conscious/subconscious nonverbal cues by the learners like gestures and facial expressions (e.g., in instances where they had difficulty verbalising the exact meaning of what they wanted to say). The discussion was transcribed and analysed using the interpretative analysis methodology (Braun and Clark, 2006). The advantage of a focus group discussion allowed the researchers to establish a rapport with the learners, which stimulated trust and cooperation essential to probe linguistic, cognitive and metacognitive skills.

A perceived disadvantage was time because the study was conducted during school hours and required the teacher to adapt her teaching schedule to accommodate the researchers. Consequently, 30-45 minutes was the target. This did not disrupt the learners' class schedule and ensured that such an intervention could realistically be included in their curriculum, should the research garner beneficial results.

Learners were required to write their second personal narrative posttest in class a week after the discussion intervention. The learners were asked to write a story based on the topic provided which was read to them and written on the board. The learners were given 30 minutes to write their story and the same procedure as the pretest narrative writing session was followed. The week's space was introduced to reduce intervention bias and ensure some transfer of skills and concepts discussed during the intervention. A delayed period was 
necessary to avoid immediate recall of the information discussed, thereby making the results unreliable.

The written narratives were analysed utilising Fey's (2001) narrative ratings framework, as adapted in Moonsamy's (2004) study on cognitive processing and narrative discourse production in children with ADHD. This format aided in the standardisation and interpretation of the narratives. The macro- and microstructures were assigned a rating score, totalling 15 (Appendix 2). Once the microstructure and macrostructure scores had been assigned and averaged, it was clear that there were no significant outliers and that the data were approximately normally distributed. Consequently, a paired samples t-test was used to analyse the narrative samples of the learners pre- and posttest. This analytic selection allowed the researchers to determine whether the mean of the dependent variable under study was the same in the two related groups; thus, comparisons could be made and conclusions were deduced (Justice, Bowles, Kaderavek, Ukrainet, Eisenberg \& Gillam, 2006).

\section{Validity, Reliability, Credibility and Trustworthiness}

The research was conducted at a single school and cannot be generalised since the sample size was small and no two contexts have identical variables. The research was conducted in a learning support context, therefore the findings can contribute to theory and practice on teaching and learning in such contexts. A pilot study and a questionnaire were used to guide the trajectory of the discussion with learners, ensuring reliability. The discussion interventions added reliability by utilising set prompts and focused engagement. All these processes were recorded and the researchers were conscious of the research and intervention process, exercising reflections and reflexivity.

The procedures, acquisition and analysis measures were regulated through standardisation and the research was precise, honest and unbiased throughout its duration. The researchers ensured this regulation by using self-monitoring techniques that focused on being objective and conscious of actions and thoughts and how these could have influenced the study. For example, the researchers strictly adhered to the predetermined questions to avoid interviewer bias and subconsciously leading the learners towards the desired answer. Prompting was limited to requesting more details or explanation of an answer instead of providing an additional point of discussion related to the question.

\section{RESULTS}

The results are aligned with the study's aims and provide information on how the intervention influenced the macro- and microstructure of the learners' written narrative scores.

\section{Summary of Overall Results}

Ten learners participated in the study and produced pre- and posttest narratives. Table 2 shows the macro- and microstructure scores of each learner's pre- and posttest narratives.

There were changes in the learners' overall story generation scores (macrostructure and microstructure). Some learners performed better in their posttest narratives following the intervention. 
Table 2: Total individual macrostructure and microstructure scores

\begin{tabular}{|ll|l|l|}
\hline \multicolumn{2}{|l|}{ Learner } & $\begin{array}{l}\text { Macrostructure } \\
\text { (Total out of 15) }\end{array}$ & $\begin{array}{l}\text { Microstructure } \\
\text { (Total out of 15) }\end{array}$ \\
\hline 1 & Pre- & 6 & 7 \\
\hline & Post- & $\mathbf{5}$ & $\mathbf{7}$ \\
\hline 2 & Pre- & 2 & 4 \\
\hline & Post- & $\mathbf{6}$ & $\mathbf{8}$ \\
\hline 3 & Pre- & 6 & 3 \\
\hline & Post- & $\mathbf{8}$ & $\mathbf{6}$ \\
\hline 4 & Pre- & 6 & 8 \\
\hline & Post- & $\mathbf{6}$ & $\mathbf{6}$ \\
\hline 5 & Pre- & 4 & 6 \\
\hline & Post- & $\mathbf{4}$ & $\mathbf{4}$ \\
\hline 6 & Pre- & 6 & 7 \\
\hline & Post- & $\mathbf{8}$ & $\mathbf{9}$ \\
\hline 7 & Pre- & 6 & 7 \\
\hline & Post- & $\mathbf{6}$ & $\mathbf{9}$ \\
\hline 8 & Pre- & 5 & 4 \\
\hline & Post- & $\mathbf{4}$ & $\mathbf{8}$ \\
\hline 9 & Pre- & 3 & 7 \\
\hline & Post- & $\mathbf{3}$ & $\mathbf{8}$ \\
\hline 10 & Pre- & 6 & 6 \\
\hline & Post- & $\mathbf{4}$ & $\mathbf{8}$ \\
\hline
\end{tabular}

Table 3 shows the mean scores of the macro- and microstructure narrative components.

When comparing the pre- and posttest results, the mean values for both the macro- and microstructure narrative components increased at posttest. Furthermore, the mean scores for the majority of the posttest macro- and microstructure subcomponents also increased.

This may imply that the learners' story generation abilities improved following the intervention. Learners who did not display increased scores maintained their pretest scores.

Table 3: Summary statistics of the quantitative results obtained pre-and posttest

\begin{tabular}{|c|c|c|c|c|c|c|}
\hline \multicolumn{2}{|c|}{ Area of assessment } & $\begin{array}{l}\text { Number } \\
\text { (N) }\end{array}$ & Mean & $\begin{array}{l}\text { Standard } \\
\text { deviation }\end{array}$ & Minimum & Maximum \\
\hline \multirow[t]{2}{*}{ Macrostructure } & Pre- & \multirow{2}{*}{10} & 5 & 1.49 & 2 & 6 \\
\hline & Post- & & 5.4 & 1.71 & 3 & 8 \\
\hline \multirow[t]{2}{*}{ Microstructure } & Pre- & \multirow{2}{*}{10} & 5.9 & 1.66 & 3 & 8 \\
\hline & Post- & & 7.3 & 1.57 & 4 & 9 \\
\hline
\end{tabular}

Increased scores may signal the learners' understanding and reflection on the writing process, their ability to deconstruct a narrative and identify and critique a narrative structure as discussed during the intervention. Bruner (1996) highlighted that making sense of your 
thinking when you learn is a starting point for metacognitive instruction. Furthermore, Moonsamy (2011) and Ellis et al. (2013) concur that verbal discussion on the thinking process clarifies thinking, thereby consolidating learning.

\section{Macrostructure Scores}

Details of the learners' grouped mean macrostructure scores at pre- and posttest are displayed in Table 4. This data indicate that the learners' basic narrative story grammar was in place. Consequently, there was a level of coherence in their writing. This was expected, as learners should have an intact narrative structure from 10 years of age (Moonsamy et al., 2009). Furthermore, the narrative structure serves as a foundation for literacy skills in Grade 4 and higher.

Table 4: Mean macrostructure scores at pre- and posttest

\begin{tabular}{|l|l|l|}
\hline Macrostructure & Pre-test & Post-test \\
\hline Setting & 0.9 & $\mathbf{1}$ \\
\hline Characters & 1.1 & $\mathbf{1 . 3}$ \\
\hline Plot & 2.5 & $\mathbf{2 . 6}$ \\
\hline Ending & 0.5 & $\mathbf{0 . 5}$ \\
\hline Total & $\mathbf{5}$ & $\mathbf{5 . 4}$ \\
\hline
\end{tabular}

The macrostructure paired samples t-test failed to reject the null hypothesis $(\mathrm{P}<0.05)$. The increase in the two narratives' mean scores therefore did not provide sufficient evidence to indicate the intervention significantly affected the learners' narrative macrostructure (Vogt, 2007) (Table 5). A possible reason for this result could be that not all learners fully understood these concepts during the intervention. It is suggested that further study in this area should be conducted.

Table 5: Paired-sample T-tests - Macrostructure

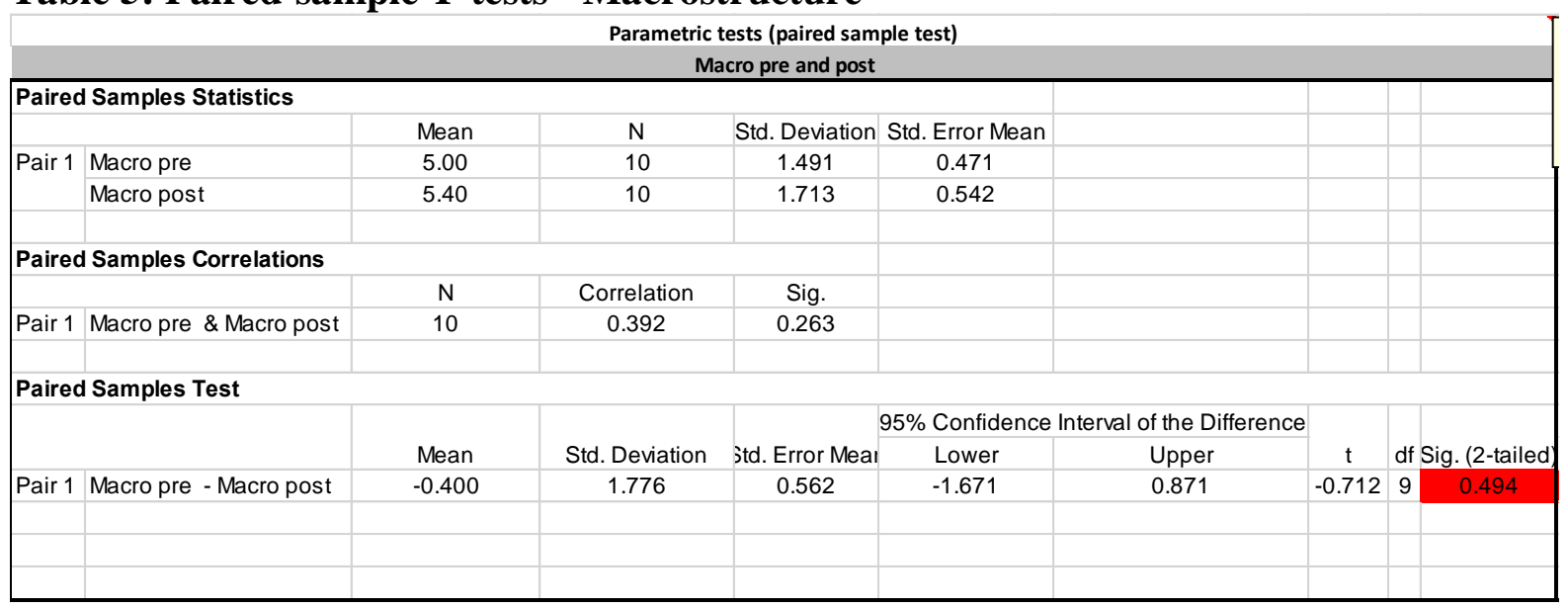

\section{Microstructure Scores}

Details of the learners' grouped mean microstructure scores at pre- and posttest are displayed in Table 6. This data indicate that some microstructure scores decreased after the intervention. These subcomponents included additive and temporal conjunctions as well as ellipses. 
Table 6: Mean microstructure scores at pre- and posttest

\begin{tabular}{|l|l|l|l|}
\hline Microstructure & Elements & Pretest & Posttest \\
\hline \multirow{4}{*}{ References } & Pronouns & 1 & $\mathbf{1}$ \\
& Definite/ Articles & 0.4 & $\mathbf{0 . 8}$ \\
& Demonstratives & 0.4 & $\mathbf{0 . 5}$ \\
\hline \multirow{5}{*}{ Conjunctions } & Additives & 1 & $\mathbf{0 . 9}$ \\
& Temporal & 0.5 & $\mathbf{0 . 3}$ \\
& Causal & 0.7 & $\mathbf{0 . 7}$ \\
& Adversatives & 0.2 & $\mathbf{0 . 3}$ \\
\hline Ellipsis & & 0.5 & $\mathbf{0 . 4}$ \\
\hline Substitutions & & 0 & $\mathbf{0 . 2}$ \\
\hline Lexical & & 0.2 & $\mathbf{0 . 4}$ \\
\hline \multirow{3}{*}{ Adjectives } & & 0.1 & $\mathbf{0 . 7}$ \\
\hline Total & Time & 0.6 & $\mathbf{0 . 6}$ \\
\hline & Place & 0.1 & $\mathbf{0 . 2}$ \\
& Manner & 0.3 & $\mathbf{0 . 6}$ \\
\hline
\end{tabular}

The decrease in conjunctions may have resulted from the learners attempting to make their narratives more sequential and concise, which was highlighted in the intervention. For example, one learner's pretest narrative utilised an additive conjunction in the sentence: 'We swam in her pool and played with the dog'. This can be contrasted with their posttest narrative whereby no additive conjunctions were utilised but there was an attempt to construct sentences that were more sequential and concise: 'I slept in the hotel. Then I had breakfast in the morning. Then I swam in the pool'.

The decrease in ellipses may have resulted from the increase in the substitution and lexical subcomponents of the microstructure. The increased use of adjectives and adverbs is the most notable. These are likely a result of the intervention since verbal discussions positively impact when the description and explanation of narratives are provided (Owens, 2014). Furthermore, Greenberg (2014) states that sharing information clarifies understanding making what is implicit explicit. Within the intervention forum, one of the learners highlighted the importance of adjectives and adverbs when writing narratives, stating that they 'give more information' and 'make the story more interesting'. This learner displayed a marked increase in his posttest microstructure score. Many learners used more adjectives and adverbs in their posttest narratives, indicating the overall benefit of explicit discussion on writing processes.

The microstructure paired samples t-test rejected the null hypothesis $(\mathrm{P}<0.05)$. The increase in the two narratives' mean scores thus provided sufficient evidence to indicate the intervention significantly affected the learners' narrative microstructure (Vogt, 2007) (Table 7). 
Table 7: Paired sample T-tests - Microstructure

\begin{tabular}{|c|c|c|c|c|c|c|c|c|c|}
\hline \multicolumn{10}{|c|}{ Micro pre and post } \\
\hline \multicolumn{10}{|c|}{ Paired Samples Statistics } \\
\hline & & Mean & $\mathrm{N}$ & Deviation & Std. Error Mean & & & & \\
\hline \multirow{2}{*}{ Pair 1} & Micro pre & 5.90 & 10 & 1.663 & 0.526 & & & & \\
\hline & Micro post & 7.30 & 10 & 1.567 & 0.496 & & & & \\
\hline \multirow{2}{*}{\multicolumn{10}{|c|}{ Paired Samples Correlations }} \\
\hline & & & & & & & & & \\
\hline & & $\mathrm{N}$ & Correlation & Sig. & & & & & \\
\hline Pair 1 & Micro pre \& Micro post & 10 & 0.098 & 0.788 & & & & & \\
\hline & & & & & & & & & \\
\hline \multicolumn{10}{|c|}{ Paired Samples Test } \\
\hline & & & & Std. Error & $95 \%$ Confide & terval of the & & & Siq. (2- \\
\hline & & Mean & Std. Deviation & Mean & Lower & Upper & $\mathrm{t}$ & df & tailed) \\
\hline Pair 1 & Micro pre - Micro post & -1.400 & 2.171 & 0.686 & -2.953 & 0.153 & -2.040 & 9 & 0.072 \\
\hline
\end{tabular}

These results show that the focus group intervention positively impacted the learners' microstructure narrative writing skills but not their macrostructure narrative writing skills. Despite statistical significance not being reached for the macrostructure component, the mean scores indicated changes. This lack of significance may have occurred due to the sample size. Furthermore, some learners did not readily participate in the intervention and it was anticipated that their posttest scores would be the same as their pretest scores. However, results revealed increased posttest scores for both the macro- and microstructure narrative components. This indicates that while statistically significant changes did not necessarily occur, even the learners who passively participated in the intervention received some benefit from the process.

\section{DISCUSSION}

This study presented the change in the macro- and microstructure components of learners with DLD when writing a narrative, following an intervention. From the results, the focus group intervention seemed to have had a statistically significant effect on the microstructure but not on the macrostructure of the learners' narratives. This indicates that the microstructural subcomponents such as substitution and adverbs seemed more highly influenced by the discussion of writing narrative processes and content. It must, however, be noted that even though the macrostructure scores were not statistically significant, most scores did not decrease at posttest which indicates that they maintained their knowledge of story grammar.

These results may indicate that even without direct teaching of each subcomponent of the narrative, the different subcomponent's scores either improved or stayed the same. The learners expanded their narratives and produced more overt explanations in their narratives.

Such details, especially in the microstructure, indicate cohesion, which learners might have become more cognisant of, taking the reader into account. Cohesion is an important aspect of narrative development and age-appropriate narrative writing as it holds the components of the story together (Owens (2014). These processes were highlighted in the intervention discussion. Hence, the importance of explicit cognitive and metacognitive strategies in narrative writing instruction needs to be frequent, if not mandatory, in classroom instruction (Vinson, 2012). Explicit instruction is foundational to creating a conscious awareness of the concepts being discussed. Furthermore, reflection on the discussion allows for new learning (Moonsamy, 2015). Therefore, the value of cognitive and metacognitive interventions such as 
the one applied in the study is noted. Explicit instruction allowed the learners to apply learning through discussion in their contexts - creating an awareness of their thinking.

Moonsamy (2014) indicates that explicit discussion impacts the learner acquiring meaning and promotes the transfer of these skills. Furthermore, tapping into prior knowledge is an essential beginning point for discussions. Thus, the learners' responses to the intervention questions on their reading behaviours indicated that they knew what narrative genre they liked reading and understood what makes a story exciting. Despite this knowledge, the learners did not incorporate these aspects into their pretest narratives. The learners indicated that they enjoyed exciting stories with mystery and adventure, yet these components were also not evident in their pretest narratives. No rising tension was included in the majority of the narratives and very few of the narratives reached a climax, indicating that although the learners knew what made a story exciting they could not translate this knowledge into their narratives. The findings also indicated that the learners understood well-organised macrostructure yet this was not transferred into their written narratives - a phenomenon which Fey (2001) highlighted amongst the participants in her study. This also concurs with Moonsamy (2011) that learners do not apply cognitive strategies spontaneously, supporting the argument that explicit instruction is essential in learning, resulting in Thinking Classrooms (Moonsamy 2014).

The findings from the current study may be due to the learners' oral and written language competency levels, confirming the literature that children with DLD have difficulty with formulating complex ideas (Owens, 2014). Moreover, these learners may have coexisting processing difficulties that might impact their attention to task and learning transfer. Literature also indicates that the spontaneous transfer of metacognitive strategies is limited (Moonsamy, 2011). Learners with DLD generally display better oral than written language skills (Ferraro \& Palmer, 2005) due to the complex cognitive demands of written narratives. Therefore, frequent explicit discussions should aid learners with DLD to build confidence in their oral skills enabling them to record their oral story before translating it into written form. The recording process will act as a scaffold, supporting their working memory and executive functions.

These oral language skills were evident in the responses to several learners' different questions during the intervention. Certain learners displayed age-appropriate language skills and cognitive insight during the discussion. One learner compared the planning process to a script used by a director when directing movie, stating that the process is important so that the director knows 'what comes next' and 'how things should be'. However, despite these observations there was little carry-over of these skills to their written narratives. Whilst this can be attributed to DLD, it is noted that the learners have the conceptual knowledge necessary to utilise both language and cognition in their narrative writing despite the lack of carry-over. This may again be attributed to the intrinsic value phenomenon because learners only carry over those skills and concepts they perceive as relevant (Greenberg, 2014). This analysis is supported by the current study where the intervention encouraged learners to apply the highlighted concepts to their own personal and individual contexts (Moonsamy, 2014). Once this was done, the learners saw the value in the skills and concepts being discussed and applied them more readily in the second narrative writing task. In the given study, the context of these learners' language abilities may also allude to fear of failure in reading and writing tasks. 
Following the focus group discussion, interesting results were revealed in the posttest narratives. The intervention highlighted that learners can benefit from modelling their written stories on stories they enjoyed reading. The learners had an opportunity to express their thoughts on such stories and they realised the benefits of this strategy. Many of the learners attempted to add more exciting elements and more descriptive elements post-intervention. More notable story climaxes were also included. The learners whose narratives improved posttest appeared more excited about their stories. The writing process appeared longer when writing their second narratives. The application of knowledge can be correlated with the improvement in narrative output. Improved written output may be attributed to the learners demonstrating a better understanding of what was required of them on the second narrative. They may also have had better insight into the writing process and knew what to include in their narrative, based on their intervention discussion. Dymock (2007) stated that it is important for learners to understand the purpose of a writing task, knowledge regarding the writing process and the strategies shared in class that can be translated into best writing practices.

A few learners, however, performed worse at posttest in the narrative writing task. The decrease in scores was largely seen in the macrostructure component. There may be several reasons for this outcome. Firstly, whilst these learners' macrostructure decreased, their microstructure values increased significantly at posttest. Consequently, the macrostructure decrease may be due to the shift in attention (cognitive resource allocation) to the narrative's microstructural components. Petersen's (2011:218) meta-analyses of narrative studies concluded that explicit instruction has an influence on the microstructural features of a written narratives. Increased microstructure elements were observed in the posttest narrative writing in the current study.

Secondly, familiarity with the required task and the process may negatively influence the learners' performance. This can be attributed to the fact the narrative writing tasks were not 'for marks' which may have lessened the intrinsic value of the task for these learners. Greenberg (2014: 151) noted that intrinsic value is an important phenomenon in any goalorientated task that learners perform and indicates that learners will not perform to their optimum capacity should they perceive a task as irrelevant, unimportant or valueless. Wittwer and Renkle (2008:57) refer to this outcome as expertise reversal effect - the learner allocates less cognitive resources to a task that may seem redundant to them.

Thirdly, the effect of the topic of the narrative must be noted since the topic changed between narratives, which may have influenced the learners' abilities to perform optimally. Dymock (2007) notes that a learner's level of familiarity with a task and their perception of the task's topic have a great influence on their ability to perform. This change in the topic may have affected the intrinsic value of the task for some learners. Moreover, a change in topic demanded different cognitive processing skills and therefore different resource allocations would have been required.

The focus group intervention structure was conducive to the learning process, and successfully engaged all learners, promoting the carry-over of the discussion's skills. Fisher (2013) described this phenomenon as being extremely important and has implications for future teaching methods and the carry-over of skills. Many of the learners experienced enlightenment moments during the intervention process and appeared to have epiphanies when discussing a skill or strategy, which they related to their contexts. One of the children indicated during the discussion group that he realised it is important to think about the reader 
when constructing narratives. This reflects pragmatic skills, where the reader's perceptive is taken into account. Reader perspectives could be a significant contributing factor to the transfer of skills and an improvement in the posttest scores as more details in the microstructure were evident.

Many ingrained practices came across in the learners' responses to certain questions whilst another learner gestured to a poster in the classroom, which highlighted the steps to writing a story. These responses indicate that the learners have a good theoretical knowledge of what they are supposed to do when they write although they do not seem to transfer this knowledge. None of the learners used a dictionary even though very few utilised the correct writing structure (both pretest and posttest). This, once again, highlights Fisher's (2013) statement that there is a need for alternative teaching methods, such as the focus-group discussion used in the intervention, for the transfer of skills and ideas to occur. Discussion groups also consolidate previous learning which is foundational for transfer. The teacher or therapist should mediate for learners, including learners with DLD, creating a connection between their prior knowledge and transfer to tasks. Such mediation confirms the prerequisite for discussion interventions, supporting Vygotsky's constructive theory. Narrative interventions through discussion forums are feasible as well as academically and socially relevant (Spencer \& Petersen, 2020).

\section{CONCLUSION}

Several key factors emerged from the study's findings including explicit instruction, prior knowledge, the context of the participant, and intrinsic and extrinsic motivation. The overall findings reflected the impact that linguistic, cognitive and metacognitive processes have on the abilities of learners with DLD when writing narratives. The authors' argument that learners seemed to have benefited from the explicit instruction on writing processes is clear. It further reflects that explicit instruction should include content and processes of a task to develop self, task and strategy awareness.

The above discussion demonstrates the importance of utilising cognitive and metacognitive processes in writing interventions and incorporating these processes into the curriculum; teachers should have a better understanding of such pedagogical processes so that they can discuss and model such strategies more readily to their learners.

This study had a small sample size and specificity of context; it nevertheless has implications for instruction when teaching learners with learning difficulties. Further research in the areas of cognition and metacognitive strategies and their relationship to the development of writing and learners' overall academics is indicated. Finally, the authors argue that explicit instruction would benefit learners who demonstrate learning difficulties in the classroom. This will help to develop a comprehensive cognitive framework that underpins instruction, reflecting the learner's potential. Furthermore, group discussion interventions employing a control group can be researched over a longer period. Instruction on narratives is foundational for academic and social development because it demands cognitive and metacognitive skills, thus benefiting all learners. 


\section{REFERENCES}

BRAUN, V \& V CLARK. 2006. Using thematic analysis in psychology. Qualitative Research in Psychology, 3(2), 77-101.

BRUNER, J. 1996. The Culture of Education. Harvard University Press.

BRUNER, J. 1996. A narrative model of self-construction. Psyke \& Logos, 17(1), 154-170.

COCKCROFT, K. 2009. Piaget's constructivist theory of cognitive development. In: WATTS J, K COCKCROFT K \& N DUNCAN (Ed). Developmental Psychology (2nd Ed.). South Africa: UCT Press.

DUNN, MW \& S FINLEY. 2010. Children's Struggles with the Writing Process: Exploring Storytelling, Visual Arts, and Keyboarding to Promote Narrative Story Writing. Multicultural education, 18(1), 33-42. Retrieved from http://www.eric.ed.gov/PDFS/EJ916844.pdf.

DYMOCK, S. 2007. Comprehension strategy instruction: Teaching narrative text structure awareness. The Reading Teacher, 61(2), 161-167.

ELLIS AK, DW DENTON \& JB BOND. 2013. An analysis of research on metacognitive teaching strategies. Procedia-Social and Behavioral Sciences, 116, 4015-4024. Retrieved from http://core.ac.uk/download/pdf/826533

FERRARO, V \& K PALMER. 2005. Speaking and Arguing: The Rhetoric of Peace and War. MA: South Hadley.

FEUERSTEIN, R, RS FEUERSTEIN, L FALIK \& Y RAND. 2006. Creating and enhancing cognitive modifiability: The Feuerstein Instrumental Enrichment Program, Part I Theoretical and conceptual foundations, Part II, Practical applications of the Feuerstein Instrumental Enrichment Program. ICELP Publications. Retrieved from http://www.thinkingconnections.org/theory/MLE.html.

FEY, ME. 2001. Evaluating school-age children's fictional narratives. Presented at the

2001 IALP World Congress/CASLPA Convention, Montreal, Quebec, Canada.

FISHER, R. 2013. Teaching thinking: Philosophical enquiry in the classroom. A\&C Black.

GILLAM, SL, J MECHAM \& RB GILLAM. 2020. The development of morphology and

syntax. In: CAPONE SINGLETON, N \& B.B. SHULMAN (Ed). Language Development: Foundations, Processes and Clinical Application. Burlington, MA: Jones and Bartlett Learning.

GILLESPIE, A. \& S GRAHAM. 2014. A Meta-Analysis of Writing Interventions for Students with Learning Disabilities. Council for Exceptional Children, 80(4), 454-473. Retrieved from https://journals.sagepub.com/doi/abs/10.1177/0014402914527238

GRAHAM, S, KR HARRIS \& L LARSEN. 2014. Prevention and Intervention of Writing Difficulties for the student with learning Disabilities. Learning Disabilities Research \& Practice, 16(2), 74 84.

GREENBERG, K. 2014. Cognitive Enrichment Advantage (CEA). In: L. Green (Ed). Schools as Thinking Communities. Pretoria: Van Schaik Publishers.

HARRIS, KR., T SCHMIDT, \& S GRAHAM. 1997. Strategies for Composition and Self-Regulation in the Writing Process. University of Maryland, reprinted with permission from Teaching Every Child Every Day: Learning in Diverse Schools and Classrooms.

JUSTICE, LM, P BOWLES, JN KADERAVEK, TA UKRAINET, SL EISENBERG \& RB GILLAM. 2006. The index of narrative microstructure: a clinical tool for analysing school-age children's narrative performances. American Journal of Speech-Language Pathology, 15(2), 177.

KOUTSOFTAS, AD. 2020. School-aged language development: Application of five domains of language across four modalities. In: Capone-Singleton N \& BB. Shulman (Ed). Communication Development: Principles, Processes, and Clinical Applications. Burlington MA: Jones\& Bartlett Learning.

KOZULIN, A. 2015. Dynamic assessment of adult learners' logical problem solving: A pilot study with the flags test. Journal of Cognitive Education and Psychology, 14(2), 219-230. https://doi.org/10.1891/1945-8959.14.2.219

LAWRENCE, B \& G HARRISON. 2014. Writing Interventions for Children in Grades One to Six with Learning Disabilities. The Division for Learning Disabilities of the Council for Exceptional Children. University of Maryland. Retrieved from 
https://www.ldatschool.ca/writing-interventions-for-children-in-grades-one-to-six-withlearning-disabilities/

LEEDY, PD \& JE ORMROD. 2005. Practical research: planning and design (8th Ed.). Upper Sadlle River, New Jersey: Pearson Prentice Hall.

MDLALO, T. 2013. The use of an English assessment test on South African English additional language (EAL) speakers from an indigenous language and cultural background: A critical evaluation (Doctoral Thesis, University KwaZulu Natal, South Africa). Retrieved from http://researchspace.ukzn.ac.za/xmlui/bitstream/handle/10413/11837/Mdlalo_Thandeka_2013.p df?sequence $=1$

McGUINNESS, C. 2005. Teaching thinking: Theory and practice. BJEP Monograph Series II, Number 3-Pedagogy-Teaching for Learning, 1(1), 107-126.

MOONSAMY, S. 2004. Executive Functioning and Narrative Discourse Production in Children with ADHD (Unpublished master's thesis, University of the Witwatersrand, Johannesburg, South Africa).

MOONSAMY, S. 2011. Effectiveness of Metacognitive Instruction on Reading Comprehension among Intermediate Phase Participants: Its link to the PASS Theory (Unpublished Doctoral thesis, University of the Witwatersrand, Johannesburg, South Africa).

MOONSAMY, S. 2014. Thinking classrooms: how to recognise a thinking classroom. In: GREEN, L (Ed). Schools as Thinking Communities, Pretoria: Van Schaik Publishers.

MOONSAMY, S. 2015. Metacognition: A tool for a strategic-thinking teacher when mediating in the classroom. In: WALTON, E \& S MOONSAMY (Eds.), Making education inclusive, Newcastle upon Tyne, UK: Cambridge Scholars Publishing.

MOONSAMY, S \& S CAROLUS. 2019. Emergent Literacy and Language support for ECD children from underserved communities in Gauteng South Africa: A Collaborative Approach. Folia Phoniatr Logop, 71,83-93. Retrieved from https://www.karger.com/Article/Abstract/493893

MOONSAMY, S, H JORDAAN \& K GREENOP. 2009. Cognitive processing and narrative discourse production in children with ADHD. South African Journal of Psychology, 39(3), 326-335.

NELSON, K. 2009. Young minds in social worlds: Experience, meaning, and memory, Harvard University Press.

NELSON, LK. 2013. Research in Communication Sciences and Disorders: Methods for Systematic Inquiry (2nd Ed.). United States of America: Plural Publishing, Inc.

OWENS, RE. 2014. Language Impairments. Language Disorders: A Functional Approach to Assessment and Intervention (6th Ed.), USA: Pearson.

PASCOE, M \& V NORMAN. 2011. Contextually relevant resources in speech-language therapy and audiology in South Africa: Are there any? South African Journal of Communication Disorders, 58(1), $2-5$

PETERSEN, DB. 2011. A systematic review of narrative-based language intervention with children who have language impairment. Communication Disorders Quarterly, 32(4), 207-220.

PREZAS, RF \& AA JO. 2017. Differentiating Language Difference and Language Disorder: Information for Teachers Working with English Language Learners in the Schools. Journal of Human Services: Training, Research, and Practice, 2(1), 1-22.

SCANLON, DM, KI ANDERSON \& JM SWEENEY. 2011. Early Intervention for Reading

Difficulties: The Interactive Strategies Approach, NY: Guilford Press.

SEIGER-GARDNER, T. 2010. Children with Language Impairment. In: SHULMAN, B \& NC CAPONE. Language Development: Foundations, Processes, and Clinical Applications, USA: Jones and Bartlett Publishers.

SPENCER, TD \& DB Petersen. 2020. Narrative intervention: principles to practice. Language, Speech and Hearing Services in Schools, 51: 1081-1096.

TAYOB, F \& S MOONSAMY. 2018. Caregivers' reading practices to promote literacy in a South African children's home: Experiences and perceptions. South African Journal of Communication Disorders, 65(1), a559. Retrieved from https://sajcd.org.za/index.php/sajcd/article/view/559 
TZURIEL, D. 2013. Mediated learning experience and cognitive modifiability. Journal of Cognitive Education and Psychology, 12(1), 59-80. Retrieved from https://connect.springerpub.com/content/sgricep/12/1/59

TZURIEL, D \& R CASPI. 2017. Intervention for peer mediation and mother-child interaction: The effect on children's mediated learning strategies and cognitive modifiability. Contemporary Educational Psychology, 49, 302-323. Retrieved from https://www.sciencedirect.com/science/article/abs/pii/S0361476X17300413?via\%3Dihub

VINSON, BP. 2012. Preschool and School-Age Language Disorders, USA: Delmar Cengage Learning.

VOGT, WP. 2007. Quantitative research methods for professionals, Pearson/Allyn and Bacon.

VYGOTSKY, L. 1934/1987. Thought and word. In Problems of general psychology, In RW Rieber \& AS Carton, First Ed, NY: Plenum.

WITT, B. 1998. Cognition and the Cognitive-Language Relationship. In: HAYNES, WO \& BB SHULMAN (Ed). Communication Development: Principles, Processes, and Clinical Applications, USA: Williams \& Wilkins.

WITTWER, J \& A RENKL. 2008. Why instructional explanations often do not work: a framework for understanding the effectiveness of instructional explanations. Educational Psychologist, 43(1):49-64. Retrieved from https://doi.org/10.1080/00461520701756420

\section{BIOGRAPHICAL NOTE}

Sharon Moonsamy is an Associate Professor in the Department of Speech-Language Pathology and the Head of the School of Human \& Community Development at the University of the Witwatersrand. Her research foci include pre-school and school-aged language, oral \& written narratives, literacy, cognition, communication disorders and intervention studies.

Natalie Barnes is a Speech-Language Pathologist, as well as a medical writer and editor. Her interest includes literacy, language and auditory processing in the school-age population. She is currently a Master's Health Research student at Stirling University, Scotland. 


\section{Appendix 1: \\ Learners Interview Discussion Questionnaire:}

\section{$\underline{\text { Reflection }}$}

Tell me, what do I need to think about when writing a story about myself?

\section{$\underline{\text { Planning Strategies }}$}

1.) Before you started writing your story, did you know what you were going to write about? How did you know?

2.) Before you started writing your story, did you know what your main story idea was? Did you know which important points you wanted to bring out in your story? How did you know? What do you believe was your main idea or key points?

3.) When you wrote your story, were you able to write details that explained your main idea? If so, how? What details do you believe explained your main idea?

\section{Monitoring Strategies}

1.) When you wrote your story, did you make sure that what you were writing was for your main idea? Or did you notice that you sometimes went off the topic?

2.) What did you do if you became 'stuck' and didn't know what to write next?

3.) Were there parts of your story that you didn't fully understand? What did you do when you were writing to help you understand what you were writing and what you wanted to say?

\section{Evaluating Strategies}

1.) Once you had finished your story, did you feel that it made sense and that anyone would be able to read it? Why? Why not?

2.) Now that you have finished your story, do you feel like you could tell me what happened in your story and answer questions based on it? Why? Why not?

3.) What do you do to check your work when you have finished writing? Tell me about this?

\section{Appendix 2}

\section{Macrostructure Analysis}

Using Fey (2001) framework, the narratives were assigned a score based on the following criteria:

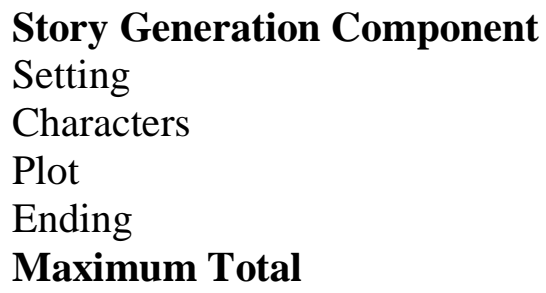

\section{Score Range}

$0-3$

$0-3$

$0-6$

$0-3$

Each component of the macrostructure is delineated as follows (Moonsamy, 2004:8): 
Setting: The setting includes explicit reference to the physical and temporal context prior to the establishment of a problem.

- 0 points: no mention of setting.

- 1 point: reference to part of the setting.

- 2 points: detailed reference to or description of the setting.

- 3 points: reference to elements that play a key role in developing the problem or resolution.

Characters: Includes explicit reference to all characters prior to the establishment of a problem.

- 0 points: no mention of characters.

- 1 point: characters are labelled, including family relations (mom, brother, sister).

- 2 points: characters are named or characteristics described.

- 3 points: characters and characteristics that play a key role in developing the plot are identified.

Plot: Points are allocated, ranging from 0-6 for the development of the plot.

- 0 points: no nuclear dyad, with no actions included.

- 1 point: no nuclear dyad, but actions are included; however, the actions are not sequenced.

- 2 points: no nuclear dyad but actions are included and sequenced.

- 3 points: nuclear dyad evident but no complications included.

- 4 points: there is a nuclear dyad, complications are included OR there is more than one nuclear dyad but one dyad is not embedded and there are no complications.

- 5 points: there is more than one nuclear dyad without one being embedded, however, complications are present.

- 6 points: there is more than one nuclear dyad and one is embedded.

For the purpose of clarification, it is stated by Fey (2001) that a nuclear dyad must contain an overtly identified problem or conflict, which must then be overtly resolved. Most dyads contain actions that move the characters towards the resolution.

The abovementioned components are described below:

- A problem is an overtly identified need, desire, conflict, danger or goal of the characters, which may be explicitly identified, often as an internal response.

- A resolution is an overt indication that the problem has or has not been resolved, giving closure to an episode.

- A complication refers to any obstacle or interruption in the actions toward a resolution that adds tension, conflict or drama. This may not result in the creation of an additional dyad.

Story Ending: This includes relevant information, character responses to the resolution and statements concerning future behaviours following the resolution of the final episode.

- $\quad 0$ points: no ending of any sort.

- 1 point: stereotyped ending (e.g. 'The End').

Per Linguam 2021 37(1):45-67

http://dx.doi.org/10.5785/37-1-969 
- 2 points: internal or external responses to the story's problem and/or resolution are provided.

- 3 points: some statement indicating a moral or that future behaviour will change as a result the characters' experiences is provided.

\section{Microstructure Analysis}

Moonsamy (2004) framework was used for this analysis. The narratives were assigned a score based on the following criteria:

\begin{tabular}{|c|c|c|}
\hline Story Generation Components & \multicolumn{2}{|c|}{ Score Range } \\
\hline \multirow[t]{4}{*}{ Reference } & \multicolumn{2}{|l|}{$0-4$} \\
\hline & Pronouns & 1 \\
\hline & Definite Articles & 1 \\
\hline & Demonstratives & 2 \\
\hline \multirow[t]{5}{*}{ Conjunctions } & \multicolumn{2}{|l|}{$0-4$} \\
\hline & Additive & 1 \\
\hline & Temporal & 1 \\
\hline & Causal & 1 \\
\hline & Adversative & 1 \\
\hline Ellipsis & \multicolumn{2}{|l|}{1} \\
\hline Substitution & \multicolumn{2}{|l|}{1} \\
\hline Lexical & \multicolumn{2}{|l|}{1} \\
\hline Adjectives & \multicolumn{2}{|l|}{1} \\
\hline \multirow[t]{4}{*}{ Adverbs } & \multicolumn{2}{|l|}{$0-3$} \\
\hline & \begin{tabular}{|l|} 
Time \\
\end{tabular} & 1 \\
\hline & Manner & 1 \\
\hline & \begin{tabular}{|l|} 
Place \\
\end{tabular} & 1 \\
\hline Maximum Totals & \multicolumn{2}{|l|}{15} \\
\hline
\end{tabular}

Each component of the macrostructure is delineated as follows (Moonsamy, 2004):

Reference: Includes the use of pronouns and definite articles to indicate referents previously identified in the narrative. For example: 'There was a girl named Lucy. She spent all of her money.'

Conjunctions: Parts of speech used to connect elements of text. There are four types of conjunctions: additive (e.g. and, furthermore), temporal (e.g. soon, then), causal (e.g. so, because) and adversative (e.g. but, however). For example: 'Lucy spent all of her money, but her mother gave her more.'

Ellipsis: This describes an indication of something the speaker leaves unsaid, which is able to be understood from the preceding or succeeding utterances. For example: 'Lucy told the shop assistant to fetch her, a doll, but the shop assistant didn't [do that].'

Substitution: Can be used where the reference is not identified or there is some new speculation to be added. For example: 'Lucy wanted a toy doll and she went to buy one.' 
Lexical: Words which are used that relate in some way to another word in the preceding text because it is a direct repetition or synonym of it. For example: 'Lucy went to a toy shop and Lucy looked at the dolls.'

Adjectives: parts of speech that describe nouns in detail. They may include: size, quantity, quality, colour, etc. For example: 'The big doll in the pink dress was more expensive than the little porcelain dolls in blue dresses were.'

Adverbs: There are three types of adverbs that are used to elaborate events: place (in, away), manner (slowly, hungrily) and time (then, now). For example: 'John went home quickly after school.' 